\title{
Cycle Ergometer and Rebound Exercises with Chest Physiotherapy - a Useful Adjunct for Sputum Expectoration in Mild to Moderately Symptomatic HIV Infected Children.
}

\begin{abstract}
Background: Sputum expectoration of lung secretions in HIV infected children with associated respiratory conditions is often difficult. Chest physiotherapy is often recommended to assist in this process but is not always successful. A erobic exercises may have beneficial effects on sputum expectoration but its safety is uncertain.

Aim: The primary aim of this study was to determine if cycle ergometer and rebound exercises are safe for mild to moderately symptomatic $H I V$ infected children and if these aerobic exercises followed by chest physiotherapy could augment sputum expectoration.
\end{abstract}

Method: Thirty six African 8-12 year old males performed 15 minutes of either cycle ergometer or rebound exercises. A modified 6 minute walking test to ensure fitness of the enrolled subjects prior to randomization was performed. Heart and respiratory rates, blood pressure and oxygen saturation was monitored for safety. Sputum expectorated was measured in a calibrated vial at baseline, 5, 10, and 15 minutes post exercise followed by 30 minutes of conventional chest physiotherapy.

Results: Total sputum produced during and post rebounding exercise was significantly higher than cycle ergometer exercises (12.6 vs.9.8mls $p=0.0002)$. The quantity of sputum obtained over each time point after rebound exercise was significantly more than cycle ergometer $(5,10 \& 15$ minutes; $p=0.0084, p=0.0002, p=0.0002$ respectively). There were no significant differences in heart and respiratory rates, blood pressure and oxygen saturation of enrolled subjects between these exercises and no cases reached the threshold for stopping the exercise.

Conclusion: Cycle ergometer and rebound exercises are safe for mild to moderately symptomatic HIV infected children. Rebound exercises followed by chest physiotherapy can be used as a safe adjunct to significantly increase sputum expectoration.

KEYWORDS: REBOUND EXERCISE, CYCLE ERGOMETER, EXPECTORATION, MODERATELY SYMPTOMATIC, HIV INFECTED CHILDREN

\section{INTRODUCTION}

The Human Immune-deficiency Virus (HIV) suppresses the immune system and makes its host susceptible to opportunistic chest infections. The thick mucus that is produced causes airway obstruction, sets up a breeding ground for bacterial infection and leads to an irreversible loss of pulmonary function (Jeena 2000). The child presents with fatigue and dyspnoea resulting in poor exercise capacity and the inability to perform simple activities of daily living and this has a profound impact on the quality of life (McGavin et al 1978). The effect of chronic respiratory limitations due to ventilatory adaptations alters lung volumes and capacities, increasing tidal volume and minute ventilation and reduces cardiopulmonary fitness at rest and during low intensity daily activities. These children develop a sedentary lifestyle with a decrease capacity for aerobic exercise leading to hyperventilation which perpetuates cardiopulmonary compromise resulting in a dyspnoea spiral (Prefaut et al 1995).

In order to improve lung function the child is often referred for chest physiotherapy to remove excess secretions and obtain sputum samples for laboratory culture. The procedure of chest physiotherapy entails postural drainage coupled with coughing, percussions and vibrations. Patients are positioned into gravity assisted postures based on the anatomy of the bronchial tree to allow secretions to be loosened and cleared from airway walls. Following this procedure tenacious thick secretions are removed thus optimizing bronchial hygiene, improving ventilation and cardiopulmonary function, slowing the proteolytic destruction of airways and

\section{Correspondence to:}

Dr Sonill S Maharaj

Head: Department of Physiotherapy

Westville Campus

University of Kwazulu-Natal

Fax: (031) 2608106

Tel: (031) 2607817

Email address: maharajss@ukzn.ac.za 
generally reducing the risk of secondary chest infections (Pryor \& Webber 1999).

In the normal population regular exercise may partially replace conventional chest physiotherapy (Zach et al 1982; Andreasson et al 1987) as aerobic exercises have positive effects on cardiopulmonary function. There is limited data showing the beneficial effects of exercise on sputum expectoration in HIV infected children with associated lung disease. Stringer (1999) noted that the participation in specific and regular exercise programs is known to improve immune function and the quality of life of an HIV infected individual with positive effects on lung function, breathing and ventilation. This augments a better physical and emotional status and delays AIDS-related complications (McClure 1993). Aerobic capacity is however substantially reduced in physically inactive adolescents with HIV infection compared to age-matched sedentary controls (Cade et al 2002). Furthermore the prescription of exercises in HIV infected children using conventional heart rate and oxygen uptake $\left(\mathrm{VO}_{2}\right)$ analog can be problematic due to errors in heart rate monitoring and technical complexity of respiratorymetabolic assessment in children, as they are physically different from adults having higher heart rates during rest and exercises (Cheatham et al 2000).

There is therefore a need to determine which exercises could be safe and beneficial for HIV infected children with associated lung disease. Therefore the primary aim of this study was to determine whether cycle ergometer or rebound exercises were safe for use in mild to moderately symptomatic HIV infected children and the concomitant effect on the volume of sputum expectorated.

\section{METHOD}

\section{Ethical approval}

Informed consent was obtained from the child's parents as approved by the King Edward VIII hospital board and the University of KwaZulu-Natal ethical review committee.

\section{Subjects}

Forty HIV infected 8-12 year old African boys referred for chest physiotherapy and sputum samples from the paediatric respiratory clinic of King Edward VIII hospital were enrolled into the study. Gender and age bias was related to physiological and biological changes that are known to occur during this period. Alveolar development begins in fetal life and matures at around 8 years with boy's peak $\mathrm{VO}_{2}$ values significantly higher than girls before puberty (Armstrong et al 1995).

\section{Inclusion Criteria}

This was based on WHO HIV and CDC HIV grading systems:

- Children with WHO stage 2 or 3 disease or CDC category A or B with mild-moderately symptomatic HIV infection were enrolled. The presenting diagnoses of these children were acute (pneumonia) on chronic infected lung disease (LIP,TB, Bronchiectasis)

- As a safety precaution completion of the six minute walking test as prescribed by the American Thoracic Society (2002) was required. Children were monitored with heart and blood pressure monitoring at three time points viz. 0,3 and 6 minutes.

\section{Exclusion Criteria}

The child was excluded if:

- he could not interpret or communicate effectively

- there was reluctance to perform the required exercise

Table 1: Baseline Characteristics

\begin{tabular}{|l|l|l|l|}
\hline $\begin{array}{l}\text { Characteristics } \\
\text { Mean } \pm \text { SD }\end{array}$ & $\begin{array}{l}\text { Bicycle Ergometer } \\
\text { Mean } \pm \text { SD }\end{array}$ & $\begin{array}{l}\text { Rebound Exercise } \\
\text { Mean } \pm \text { SD }\end{array}$ & p-value \\
\hline Age $(\mathrm{yr})$ & $10.1(8-12)$ & $9.8(8.1-11.9)$ & $\mathrm{Ns}$ \\
\hline Body Mass $(\mathrm{kg})$ & $35.3 \pm 8.2$ & $36.5 \pm 6.0$ & $\mathrm{~ns}$ \\
\hline Body Height(cm) & $145.8 \pm 6.9$ & $142.2 \pm 7.6$ & $\mathrm{~ns}$ \\
\hline Thigh Length (cm) & $35.2 \pm 1.9$ & $34.6 \pm 2.4$ & $\mathrm{~ns}$ \\
\hline Leg Length(cm) & $13.1 \pm 1.4$ & $12.5 \pm 1.1$ & $\mathrm{~ns}$ \\
\hline Foot Length(cm) & $33.9 \pm 1.7$ & $32.5 \pm 2.1$ & $\mathrm{~ns}$ \\
\hline $\begin{array}{l}\text { CDC HIV status } \\
\text { A }\end{array}$ & 3 & 2 & $\mathrm{~ns}$ \\
\hline B & 15 & 16 & $\mathrm{~ns}$ \\
\hline $\begin{array}{l}\text { WHO Categories } \\
11\end{array}$ & 2 & 3 & $\mathrm{~ns}$ \\
\hline 111 & 16 & 15 & $\mathrm{~ns}$ \\
\hline Respiratory Rate(min) & 28 & 31 & $\mathrm{~ns}$ \\
\hline Heart Rate (beat/min) & 81 & 79 & $\mathrm{~ns}$ \\
\hline $\begin{array}{l}\text { Blood Pressure (mm/Hg)- } \\
\text { prior to walking test }\end{array}$ & $121 / 67$ & $126 / 73$ & $\mathrm{~ns}$ \\
\hline Sputum (ml) & 0.9 & $\mathrm{~ns}$ \\
\hline
\end{tabular}


Table 2: Sputum Production at different time points per exercise performed

\begin{tabular}{|l|l|l|l|}
\hline $\begin{array}{l}\text { Time } \\
(\mathbf{m i n})\end{array}$ & $\begin{array}{l}\text { Cycle Ergometer } \\
\text { Sputum }(\mathbf{m l}) \\
\text { Mean } \pm \text { range }\end{array}$ & $\begin{array}{l}\text { Rebound Exercise } \\
\text { Sputum }(\mathbf{m l}) \\
\text { Mean } \pm \text { range }\end{array}$ & $\mathrm{p}$-value \\
\hline 0 & $0.89(0.5-1.3)$ & $1.10(0.6-1.8)$ & $\mathrm{Ns}$ \\
\hline 5 & $1.41(0.7-2.1)$ & $1.91(1.3-2.6)$ & $\mathrm{P}=0.0084$ \\
\hline 10 & $2.10(1.3-2.7)$ & $3.13(2.4-4.0)$ & $\mathrm{P}=0.0002$ \\
\hline 15 & $2.30(1.8-3.0)$ & $3.83(3.1-4.8)$ & $\mathrm{p}=0.0002$ \\
\hline 30 & $3.10(2.6-3.7)$ & $2.74(2.0-3.6)$ & $\mathrm{ns}$ \\
\hline Accumulative & $9.80(8.3-11.1)$ & $12.6(10.7-13.9)$ & $\mathrm{p}=0.0002$ \\
\hline
\end{tabular}

Table 3: Blood Pressure recordings $(\mathrm{mm} / \mathrm{Hg})$

\begin{tabular}{|l|l|l|}
\hline & Cycle Ergometer & Rebound Exercise \\
\hline Rest (post walking test) & $131 / 77$ & $136 / 83$ \\
\hline 5mins & $141 / 85$ & $148 / 91$ \\
\hline 10mins & $144 / 82$ & $135 / 88$ \\
\hline 15mins & $146 / 87$ & $146 / 91$ \\
\hline
\end{tabular}

\section{Procedure}

On completion of the walking tests the subjects rested for thirty minutes during which they were randomly and equally assigned by a computer into two groups.

\section{Group A}

These children cycled on the Monark Model 1818 ergometer with movable handle bars and set with a pedal rate of 60 revolutions per minute and no resistance.

\section{Group B}

Performed two feet bouncing on a mini-trampoline Model T-rebound with 36 springs and a circumference of 1 metre fitted with handle bars for safety. The bounce frequency was a minimum of 60 per minute with a height of $10 \mathrm{~cm}$.

The following descriptive characteristics and measurements were taken and averaged for the subjects in the respective groups (table 1).

\section{Measurements}

The body mass, height, thigh length, leg length and foot length of all subjects were measured. All measurements were done without shoes. The subject's mass was measured on a balance beam scale and height was measured using a wallmounted stadiometer. Thigh length was measured from the greater trochanter to the lateral femoral condyle. Leg length was measured from the lateral femoral condyle to the lateral malleolus and foot length was measured from the lateral malleolus to the fifth metatarsal head.

\section{Exercise Procedure}

Each child was familiarized with the respective exercise. Before commencement (and during) the exercises, heart and respiratory rates, blood pressure and oxygen saturation was monitored and recorded using a portable DatexOhmeda Cardiocap 5 which was tested and calibrated by a technician. The child was encouraged to cough out sputum into a calibrated vial. All these values were recorded as the resting values.

Completion of a successful revolution or bounce was signaled by an electronic metronome. Both groups had five minute of the respective exercise alternating with 3 minutes of rest. This was repeated three times with the heart and respiratory rates, oxygen saturation and blood pressure being continuously monitored and recorded at 5, 10 and 15 minutes respectively. As a safety precaution heart rate maximum was set at within 10 beats of $80 \%$ of age predicted (220-age) maximum (American College of Sports Medicine 1995). Sputum expectorated was also recorded at these time points. Throughout the exercise period the researchers monitored for subjective fatigue, dyspnoea and respiratory distress, profuse sweating, an inability to maintain the desired exercise intensity or unsteady gait which were used to as a threshold to indicate that the child was approaching or reached his maximum exertion (Rowland et al 1990). A $25 \%$ increase in systolic and diastolic blood pressure above resting blood pressure during exercise was regarded as an indication for stopping the activity (Lim et al 1996).

On completing the exercise the child rested for 3 minutes followed by chest physiotherapy performed by a senior physiotherapist who was blinded to the type of exercise. The child assumed six postural drainage positions. In each position the chest wall was percussed for 5 minutes followed by deep-breathing exercises combined with vibration on expiration, forced expirations and vigorous coughing. Completion for all drainage positions required approximately 30 minutes and conformed to international standards for chest physiotherapy as prescribed by McIlwaine et al (1997). Post-chest physiotherapy the total volume of sputum expectorated was recorded.

\section{Statistical Analysis}

All data was analyzed with SPSS 11.5 for windows (SPSS Inc Chicago, IL). Descriptive analyses were preformed using Student t-test for continuous variables and Chi-squared and Fisher exact test for categorical variables. Two tailed $\mathrm{p}$ values of $\mathrm{p}<0.05$ were considered statistically significant.

\section{RESULTS}

Two children did not complete the walking test. One child felt nausea during 
rebound exercise and another did not complete cycle ergometry due to pain experienced in his right knee. A total of 36 children completed the study and all values depicted and tabulated are the mean for the subjects in the relevant areas.

\section{Physical Characteristics}

The descriptive characteristics and measurements of subjects in both exercise groups are tabulated in table 1. Age, body mass, body height, thigh, leg and foot length did not differ significantly between the groups.

\section{Oxygen Saturation, Heart and Respi- ratory Rates}

Mean heart and respiratory rates at rest and during the respective exercises did not differ significantly between the groups (figure 1 and 2). The average heart and respiratory rates that were attained were within the average rates for normal children performing aerobic exercises. Oxygen saturation did not differ significantly between the groups (figure 3).

\section{Blood Pressure}

No significant differences existed between the groups however children in both groups appear to be in the hypertensive range before commencement of the exercises (table 3) and remained high during cycle ergometry with erratic readings occurring during rebound exercise as compared to normal children in this age group.

\section{Sputum Volume}

Average sputum volumes for the groups were high at all points (figure 4). Postchest physiotherapy the cycle ergometer group produced a total of $9.8 \mathrm{ml}$ and rebound exercise $12.6 \mathrm{ml}$. The sputum volume produced at 10 minutes of rebound exercise was equivalent to that produced by 15 minutes of cycling $6,1 \mathrm{mls}$ vs $6.7 \mathrm{mls}$ respectively.

\section{DISCUSSION}

Although all the enrolled subjects presented with cardiopulmonary compromise secondary to HIV related lung diseases, ninety percent completed the exercises without compromising their health status; indicating that aerobic
Figure 1: Heart rate (beats/min)

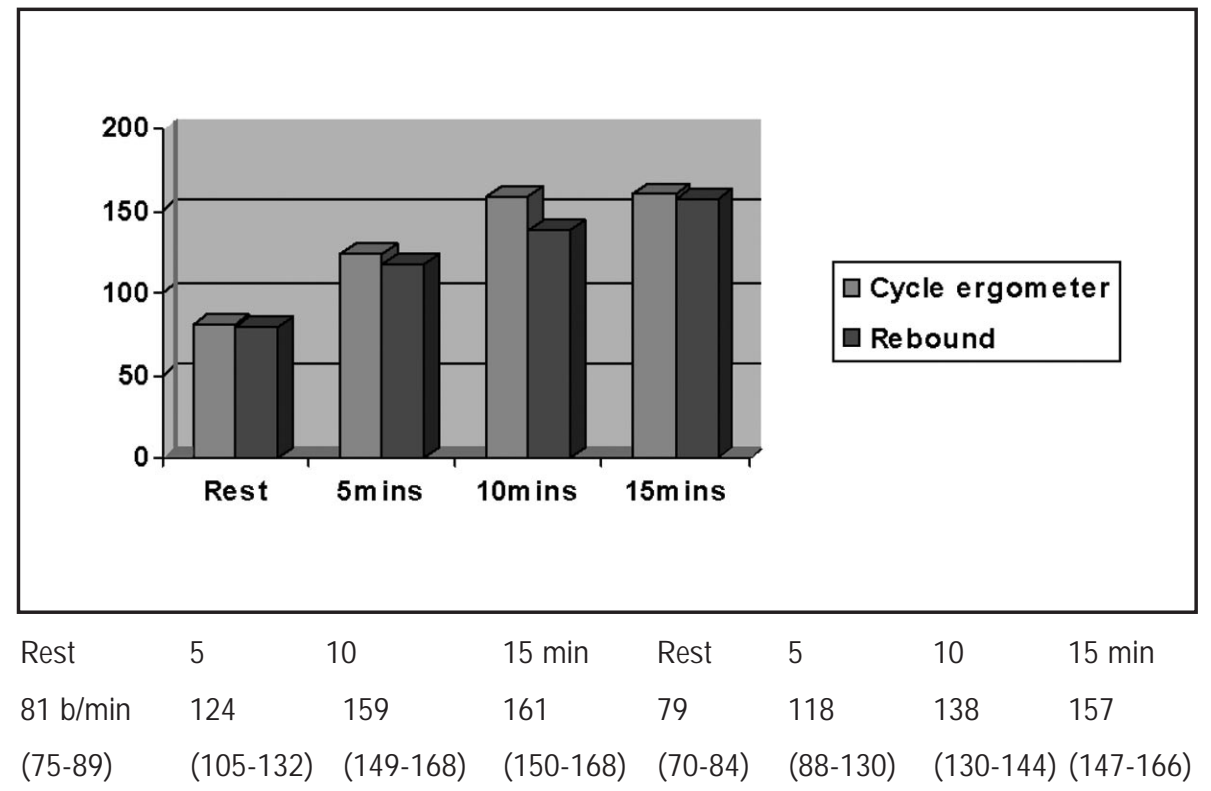

Figure 2: Respiratory rate (per minute)

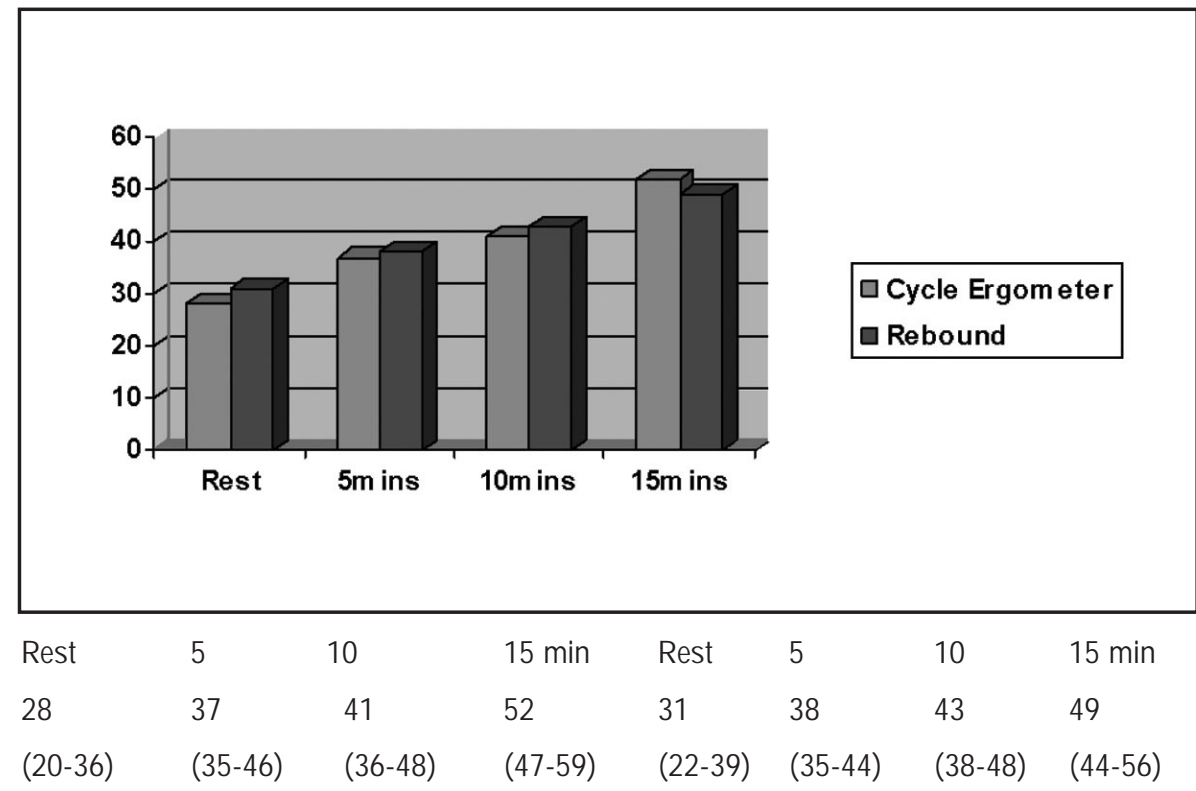

Figure 3: Oxygen Saturation (\%)

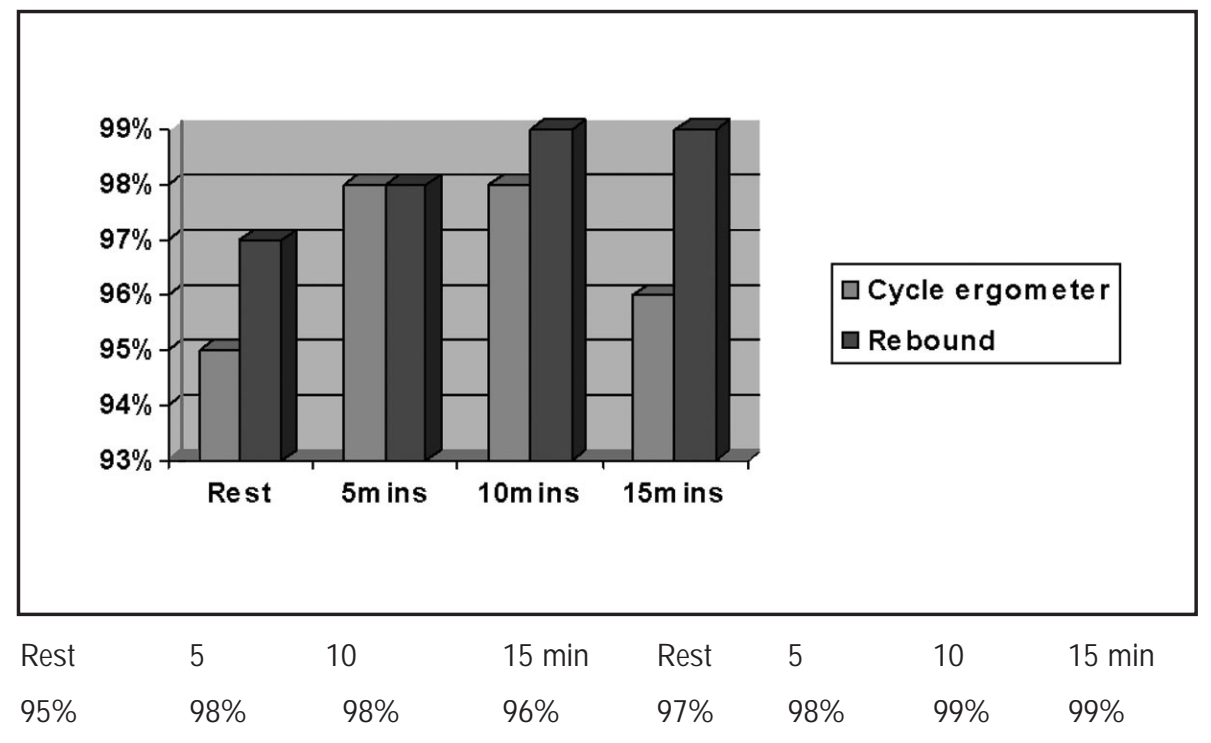


exercises is safe to perform in the short term. Dyspnoea is probably the most prominent of the varied sensations that prevent athletes, untrained individuals and patients with cardiopulmonary disorders from exercising (Jones 1984). When exercising, these individual hyperventilate to compensate for the increased workload with a shortened inspiratory time which shortens and flattens the diaphragm's force of production (Poole et al 1997). Both exercises in this study showed an increase in respiratory rates. The repetitive bouncing movements of the rebounder probably enhanced diaphragm movements with a concomitant effect on the force of sputum production. The elastic nature of the lung together with whole body movements increases the recoil pressure of the lungs and enables trapped sputum to be expectorated. Exercise and eucapnic hyperventilation accelerate mucociliary transport (Wolff 1977). The rebounding effect augments oscillation of airflow which enhances the loosening of mucus from the airway walls. Coupled with the movement of the diaphragm which is enhanced by gravity, the overall effect is similar, albeit more effective, than the active cycle of breathing techniques which has been shown to improve both clearance of broncho-pulmonary secretions and lung function (Pryor \& Webber 1999).

In this study both cycle ergometer and rebound exercises had beneficial effects on sputum production because both activities augment the active cycle of the breathing technique which is effective in sitting or standing. The active cycle of breathing may be performed with or without a physiotherapist providing vibration, percussion and shaking. With ergometer exercise, the sitting posture and the rhythmical movement of the lower limbs augment diaphragm movements while with rebound exercise the movement of the diaphragm, lungs and inspiratory and expiratory muscles is subjected to the rhythmical action of gravity. It is this rhythmical gravity assisted force that has an enhanced positive effect on the respiratory system, the loosing of secretions and the facilitation of the movement of these secretions. This could explain the significant increase in sputum volume in rebounding as compared to cycling. Furthermore, children in this study enjoyed participating in either of the two physical activities and regular performance of these safe activities could alter the dyspnoea spiral to allow reversal of deconditioned cardiopulmonary system. These results are similar to that observed by Salh et al (1989) in which physiotherapy and a safe home program of exercise increased sputum expectoration in patients with cystic fibrosis suggesting that exercise should be used to augment rather than replace conventional chest physiotherapy.

Blood pressure monitoring during exercise can be used to limit exercise in heart or lung disease with an increase of $25 \%$ above baseline being used as a cutoff. The hypertensive readings at rest prior to randomization to cycling or rebound could be related to the walking tests that the children performed.

Olsen et al (2002) found that systolic blood pressure increase with exercise time, reaches a peak at 12 minutes at a heart rate of 160 beats per minute with diastolic pressure remaining constant throughout the exercise. During this study the cycle ergometer group seems to confirm these findings but the erratic and fluctuating blood pressure noted with rebound exercise is probably due to the nature of the effects of gravity on our readings. Also with rebounding the use of fluctuating positive and negative lower body positions correlates to changes in central and thoracic blood volumes which results in predictable changes in central venous pressure (Coast et al 1998). On comparison therefore cycling has a more localized hyperaemia whereas rebounding exercises has a more general effect on circulation thus accounting for a slightly higher than normal blood pressure readings between these two modes of exercises.

\section{CONCLUSION}

The results of this study indicated that rebound exercise and cycling on the bicycle ergometer are safe exercises for mild to moderately symptomatic HIV infected children. Rebound exercise produced a larger volume of sputum in a shorter period of time when compared to cycle ergometry. Rebound exercises therefore appears to mobilize peripheral lung secretions more effectively than cycle ergometry and can be used to significantly enhance sputum expectoration as an adjunct to conventional chest physiotherapy.

\section{LIMITATIONS TO THE STUDY}

The inclusion criteria did not take into account the child's previous exposure to cycle ergometer or rebounding activity before being assigned to the groups. Although the researchers motivated subjects to cough up all secretions, some secretions could have been swallowed or saliva could have been included in the sample thereby affecting the sputum volumes but these would be represented in both arms of the study. Dried sputum mass was not undertaken in this study.

\section{ACKNOWLEDGEMENT}

The researchers would like to thank the physiotherapy staff of King Edward VIII hospital and the surgical ICU manager for the use of their portable DatexOhmeda Cardiocap 5.

\section{REFERENCES}

American College of Sports Medicine 1995. General principles of exercise prescription. Baltimore (MD): Williams and Wilkins 5th edition

American Thoracic Society 2002. The six minute walking test. American Journal of Respiratory Oritical Care Medicine 166: 111-117

Andreasson B, Jonson B, Kornfalt R, Nordmark E 1987. Long term effects of physical exercise on working capacity and pulmonary function Acta Paediatric Scandia 76: 70-75

Armstrong N, Kirby BJ, Mcmanus AM, Welsman JR 1995. Aerobic fitness of prepubescent children. Annals of Human Biology 22: 427-441

Cade WT, Peralta L, Keyser RE 2002. Aerobic capacity in late adolescents infected with HIV and controls. Paediatric Rehabilitation 5: 161-169

Cheatham CC, Mahon AD, Brown JD, Bolster DR 2000. Cardiovascular responses during prolonged exercise at ventilatory threshold in boys and men. Medicine and Science in Sports and Exercise 32: 1080-1087 
Coast RJ, Kroy JA, Akers RM, Dahl T 1998. Effects of lower body pressure changes on pulmonary function. Medicine \& Science in Sports and Exercise 30 (7): 1035-1040

Jeena PM 2000. An approach to Interstitial Lung disease in children. South African Respiratory Journal 6(2): 72-78

Jones NL 1984. Dyspnoea in exercise. Medicine and Science in Sports and Exercise 16(1): 14-19

Lim PO, MacFayden RJ, Clarkson PB, MacDonald TM 1996. Impaired exercise tolerance in hypertensive patients. Annals of International Medicine 124: 41-55

McCure J 1993. The role of physiotherapy in HIV and AIDS. Physiotherapy 79(6): 388-393

Mc Gavin CR, Artvinli H, Naoe H, McHardy GJ 1978. Dypsnea, disability and walking distance: comparison of estimates of exercise performance in respiratory disease. British Medical Journal 2: 241-243
Mcllwaine PM, Wong LT, Peacock J 1997.Long term comparative trials of conventional postural drainage versus positive expiratory pressure in cystic fibrosis. The Journal of Pediatrics 131(4): 571-573

Osen R, Amlie A, Omvik P 2002. Blood pressure monitoring. Journal of Applied Physiology 7: $149-156$

Prefaut C, Varray A, Vallet G 1995. Pathophysiological basis of exercise training in patients with chronic obstructive lung disease. European Respiratory Review 5: 27-32

Poole DC, Sexton WL, Farkas GA, Powers SK, Reid M 1997. Diaphragm structure and function in health and disease. Medicine and Science in Sport and Exercise 6: 738-754

Pryor JA, Webber BA 1999. Physiotherapy for respiratory and cardiac problems. London: Churchill Livingstone

Rowland TW, Staab JS, Unnithan VB 1990. Mechanical efficiency during cycling in prepu- bertal and adult males. International Journal of Sports Medicine 11: 452-455

Salh W, Bilton D, Dodd M, Webb AK 1989. Efect of exercise and physiotherapy in aiding sputum expectoration in adults with cystic fibrosis. Thorax 44:1006-1008

Stringer WW 1999. HIV and aerobic exercise. Sports Medicine 28(6): 389-395

Wolff RK, Dolovich MB, Obminski G, Newhouse MT 1977. Effects of exercise and eucapnic hyperventilation on bronchial clearance in man. Journal of Applied Physiology 43: 46-50

Zach M, Oberwaldner B, Hausler F1982. Oystic fibrosis: Physical exercise versus chest physiotherapy. Archives of disease in Childhood 57: 587 - 589

\section{Membership Renewal Forms for 2009 have now been sent out.}

Please complete the form in full, as all information is critical and necessary to ensure that the SASP operates as a professional entity with vital statistical information at our fingertips.

\section{PLEASE NOTE THAT ALL MEMBER FORMS MUST BE RECEIVED}

\section{BEFORE 31 DECEMBER 2008}

\section{AND ALL PAYMENTS MUST BE RECEIVED BEFORE THE 28 FEBRUARY 2009. PLEASE ALSO NOTE THAT OUR NEW FAX NUMBER IS: 0865598237}

Once Head Office has received the completed membership form and upon acceptance of the application, member data will be captured and an invoice will be sent. Once payment has been received a receipt together with your membership card will be posted or e-mailed to you. Failure to pay will result in immediate suspension from the SASP and a removal of your name from the Malpractice Insurance Scheme.

\section{DO YOU WANT TO ADVERTISE IN ANY OF OUR PUBLICATIONS?}

For any questions or queries, please contact Americo at (011) 561-3290 or pr@saphysio.co.za 
CPD Disclaimer: All information contained in these course advertisements has been carefully listed, viewed and edited. The SASP, nor anyone involved in the production of the publication, will be held liable for any incorrect information published regarding the accreditation status or number of CEU units available for the courses advertised herein.

\begin{tabular}{|c|c|}
\hline \multicolumn{2}{|c|}{ CPD made easy... } \\
\hline The benefits: & How to start: \\
\hline Study in your own time, at your own pace, in your own space & * Select your articles from a current catalogue \\
\hline - Select articles that are selected by health professionals & * Complete and post the order form \\
\hline Choose from two catalogues a year & * Study the article, complete the answer sheet \\
\hline - Articles are accredited by the SA Academy of Family Practice & * Wait for your CPD certificate \\
\hline \multicolumn{2}{|c|}{ Get our current catalogues by phone (011) 646-1838, fax (011) 646-0474, or visit our website www.therapymediacpd.co.za } \\
\hline \multicolumn{2}{|c|}{ The Therapy Media CPD Trust } \\
\hline
\end{tabular}

CLASSIFIEDS

\section{SITUATIONS VACANT}

Benoni: Full-time physio required in busy orthopaedic practice. Rooms and hospital work. Please contact (011) 849-3721 (AM), or 083 227-2915 $(\mathrm{A} / \mathrm{H})$, or $0827809378(\mathrm{~A} / \mathrm{H})$. Fax CV to $(011) 425-3370$.

Modderfontein: Newly qualified or experienced physio required for full-time position in busy practice. Special interest- golf injuries. Call Samantha, (011) 606-3096 or 083 226-6529.

Sandton / Illovo: Energetic physiotherapist needed for busy, dynamic, private practice. Mostly OMT, sports, orthopaedics, craniosacral therapy. To start Dec08/Jan 09. Please Contact Analita on (011) 268-0331 or email CV to physiotherapist@global.co.za.

JHB South, Lenasia: Full-time physio required for private practise. E-mail CV to hemaphys@yahoo.com

Sandton: Physio required for dynamic sports and spinal practice. Excellent training with current post-grad lecturer. Future partnership prospects.

E-mail CV:stavs@mweb.co.za

Sunward Park: Physiotherapist needed. Full-time / part-time position available in a hospital and out-patient practice. Contact Leigh, (011) 913-3602 / 3 or 082 908-7713.

Regional reps wanted, nationally with existing physio customer base. Will ideally suit reps, independent agents already calling on physio's. Very generous commission offered on easy to sell product. Please send CV or similar to steve@fortax.co.za
Port Elizabeth: Full-day position available in practice in medical centres. Must be able to work independantly as well as part of a team. Out- as well as in-patients. Contact Leonora Ferreira at (041) 374-7001; 083 409-5486; leonora@hinet.co.za

Louis Trichardt: Physio needed for busy well established practice. Sal neg. Elmien, 082 781-4249

Brits: Besige praktyk benodig 'n voldag, permanente fisioterapeut en lokum vir kamer- en hospitaalwerk vanaf Januarie 2009. Aangename werksomstandighede. Kontak, Alta / Liesel, (012) 252-6318.

Mooinooi: Physio required in a well established practice. Sal neg. General practice. 082 646-1680.

Rustenburg: Full-day position available from Jan 09. Hospital and rooms. Pleasant working conditions in multidissiplinary setup. Competitive package. Contact Sarie Louise, 082 578-6597.

Hazyview: Voltydse / deeltydse fisioterapeut benodig vir spreekkamerwerk. Kontak Carin by 082 960-7919.

Southern Johannesburg: Full-time physiotherapists needed in busy hospital and out-patient practice. Emphasis on in-service training and continued professional development. Lovely working environment. Contact Barry on (011) 907-3647 or Joanne on (011) 435-6177.

Edenvale: Full-time physiotherapy position available for out-patient orthopaedic and sports practice. Strong emphasis on continuing education. Contact Philippa, 072 620-6461/ Anne-Margaret, 082 463-3720 or email CV's to smwphysio@wol.co.za
Pta: Voldag fisio benodig vir hospitaal en spreekkamer werk vanaf 1 Januarie 2009. Adele Steenkamp, (012) 335-4351.

\section{FOR SALE}

Practice closing, selling the following: us / interferential machine, 3 wooden plinths, full plastic skeleton, 2 trollies, traction with bed. Phone Claudine, (011) 646-1838 or (011) 646-7594.

\section{LOCUMS}

Durban: Locum needed from 22nd Dec 08 to 05th Jan 09 at the SAN. Good rumeneration offered/flexi hrs. Contact Vanesh, 083 293-2145, (031) 201-3025.

\section{Roodepoort / Wesrand area:}

Langtermyn locum/assistent benodig in gevestigde praktyk vir 2008/2009. Kontak Melinda Strauss, 082 857-4475 of (011) 762-7064.

\section{PRACTICE FOR SALE}

Pta: Practice for sale. For information contact me at golfhysio@mweb.co.za

\section{GENERAL}

\section{Patient account administration -} capturing of fees, EDI to Funds and following up of outstanding amounts. Benefit from improved cash flow. Focus on your practice and leave the administration to us. Mostly Gauteng area. We have been specialists in medical accounts for more than 8 years. Contact Philip Potgieter personally at 083 452-4550. 